\title{
USULAN PERANCANGAN KUISIONER PENILAIAN KINERJA TENAGA KEPENDIDIKAN PERGURUAN TINGGI SWASTA DENGAN METODE 360 DEGREE FEEDBACK
}

\author{
Fransisca Debora ${ }^{1}$, Zulfa Fitri Ikatrinasari ${ }^{2}$ \\ ${ }^{1}$ Magister Teknik Industri / Teknik Industri / Universitas Mercu Buana / \\ fransisca.debora91@gmail.com \\ ${ }^{2}$ Magister Teknik Industri / Dosen Teknik Industri / Universitas Mercu Buana / \\ zulfafitri@gmail.com
}

\begin{abstract}
The 360 degree feedback method is an assessment that can provide performance feedback from yourself, superiors, subordinates, and co-workers. The results of the implementation of this performance can be a monitoring and evaluation system for the employee and related employees to develop and set the target work and the determination of reward (reward). In this 360 degree feedback method found also an obstacle in which the emergence of internal assessment among employees.
\end{abstract}

Keywords : performance appraisal, 360 degree feedback assessment method

\begin{abstract}
ABSTRAK
Metode 360 degree feedback merupakan penilaian yang dapat memberikan umpan balik kinerja dari diri sendiri, atasan, bawahan, dan rekan kerja. Hasil dari penerapan kinerja ini dapat menjadi sistem monitoring dan evaluasi bagi pihak kepegawaian dan pegawai terkait untuk mengembangkan dan menetapakan target kerja dan penentuan penghargaan (reward). Pada metode 360 degree feedback ini ditemukan juga penghambat dimana akan munculnya penilaian internal antar pegawai.
\end{abstract}

Kata Kunci : penilaian kinerja, metode penilaian 360 degree feedback

\section{PENDAHULUAN}

Salah satu faktor dalam peningkatan produktivitas performansi suatu organisasi yaitu kualitas dari Sumber Daya Manusia (SDM) yang dimiliki. Kualitas SDM dapat digambarkan berdasarkan keahlian ataupun kompetensi yang dimiliki pegawai untuk mengoptimalkan penilaian prestasi kinerja tenaga pegawai di dalam suatu organisasi. Dalam industri jasa atau pelayanan jasa terkhusus dalam bidang jasa pendidikan banyak yang belum mempunyai pegawai yang memiliki kompetensi keahlian dibuktikan dengan rendahnya nilai tambah (value added) yang diberikan pegawai kepada institusi yang bersangkutan.

Dalam dunia pendidikan terkhusus Perguruan Tinggi Swasta (PTS) terdapat 2 (dua) penggolongan pegawai yaitu tenaga pendidik dan tenaga kependidikan. Tenaga pendidik yaitu pegawai yang melakukan kegiatan Tridharma pendidikan yaitu penelitian, pengabdian dan pengajaran. Sedangkan tenaga kependidikan yaitu pegawai yang membantu dalam kegiatan operasional berjalannya kegiatan belajar mengajar (KBM). Penilaian kualitas SDM atau penilaian performansi di PTS salah satunya di PTS X belum dilakukan dengan secara optimal terutama penilaian performansi dari tenaga kependidikan. Penilaian performasi tenaga kependidikan hanya ditentukan dari kedisiplinan jam kerja dan sehingga belum adanya penilaian yang jelas. Sedangkan penilaian performansi dari tenaga pendidik sudah 
menggunakan Beban Kerja Dosen (BKD) yang sudah terdapat unsur Tridharma yaitu penelitian, pengabdian dan pengajaran yang di lakukan monitoring dan evaluasi setiap semester atau per 6 (enam) bulan. Sistem penilaian BKD tidak diterapkan kepada penilaian perfomansi tenaga kependidikan. Maka dari itu penelitian ini dilakukan untuk mengembangkan sistem penilaian performansi berdasarkan kompetensi yang dapat mengakomodir penilaian performasi bagi tenaga kependidikan.

Kompetensi merupakan bagian dalam dan selamanya ada pada kepribadian seseorang dan dapat memprediksikan tingkah laku dan performansi secara luas pada semua keadaan atau situasi dan job tasks (Spencer, 1993). Faktor-faktor kompetensi menurut Spencer terdapat 20 (dua puluh) faktor kompetensi, dari kedua puluh faktor kompetensi tersebut hanya ada 7 (tujuh) faktor kompetensi yang akan dibutuhkan secara umum dalam peningkatan produktivitas kualitas performasi pegawai terkhusus untuk tenaga kependidikan. Ketujuh kompetensi tersebut diantaranya disiplin, inisiatif, berprestasi, komitmen pada organisasi, melayani, kerjasama dan proaktif.

Penilaian kinerja kompetensi tenaga kependidikan di PTS X dapat mempengaruhi produktivitas performansi pegawai dimana dapat mempengaruhi adanya penghargaan (reward) terhadap performasi pegawai, sehingga penghargaan atau insentif yang diberikan oleh institusi sesuai dengan keseharusannya.

\section{KAJIAN TEORI}

\subsection{Prestasi Performansi Kinerja}

Penilaian performasi merupakan suatu proses penilaian kompetensi atau prestasi kinerja pegawai yang dilakukan oleh perusahaan secara sistematik berdasarkan pertimbangan pekerjaan yang diberikan kepadanya (Dessler, 1997). Sedangkan menurut Handoko (1996) penilaian performasi merupakan proses melakukan evaluasi dan penilaian prestasi kerja pegawai. Kegiatan tersebut dapan memperbaiki keputusan-keputusan personalia dan memberikan umpan balik (feedback) kepada pegawai terkait pelaksanaan kinerja mereka.

Penilaian prestasi performasi menurut Stoner et al. (1996) merupakan proses yang meliputi:

1. Penetapan standar prestasi performansi.

2. Penilaian prestasi performansi aktual pegawai.

3. Pemberian umpan balik kepada pegawai yang bertujuan memotivasi pegawai untuk meningkatkan produktivitas dan menghilangkan kemerosotan yang mempengaruhi performansinya.

Sedangkan yang dimaksud dengan dimensi kerja menurut Gomes (1995) memperluaskan dimensi prestasi performansi kinerja pegawai yang berdasarkan:

1. Quantity work, jumlah kerja yang dilakukan dalam suatu periode waktu dan kesiapannya

2. Quality of work, kualitas kerja berdasarkan syarat-syarat kesesuaian dan kesiapannnya.

3. Job knowledge, luasnya pengetahuan mengenai pekerjaan dan keterampilannya.

4. Creativeness, keaslian gagasan-gagasan yang dimunculkan dan tindakan-tindakan untuk menyelesaikan persoalan-persoalan yang timbul.

5. Cooperation, kesetiaan untuk bekerjasama dengan orang lain.

6. Dependability, kesadaran dan kepercayaan dalam hal kehadiran dan penyelesaian kerja.

7. Initiative, semangat untuk melaksanakan tugas-tugas baru dan dalam memperbesar tanggung jawabnya.

8. Personal qualities, menyangkut kepribadian, kepemimpinan, keramah-ramahan, dan integritas pribadi. 
Tujuan penilaian performansi kinerja pegawai menurut Nurmianto dan Wijaya (2003) tidak terlepas dari tujuan pokok diantaranya:

1. Untuk tujuan administrasi personalia

a. Menjadi dasar pembuatan keputusan manajemen mengenai promosi, mutasi, demos dan pemberhentian pegawai.

b. Menjadi dasar dalam pemberian balas jasa.

c. Menjadi dasar dalam menetapkan program pendidikan dan pelatian guna mendukung efektivitas unit-unit kerja organisasi.

d. Menjadi dasar menetapkan program pendidikan dan pelatihan guna mendukung efektivitas unit-unit kerja organisasi.

e. Menjadi dasar penetapan kriteria untuk seleksi dan penetapan pegawai.

f. Memberikan data mengenai produktivitas organisasi secara keseluruhan atau uni kerja dan individu pegawai khususnya.

2. Untuk tujuan bimbingan dan konseling

a. Merupakan forum pembimbingan dan konseling antara atasan dan bawahannya untuk memperbaiki atau mengembangkan kecakapan pegawai.

b. Mengidentifikasi kelebihan atau kekurangan pegawai yang menjadi salah satu dasar pertimbangan dalam melibatkan pegawai pada program pelatihan dan pengembangan pegawai.

c. Sebagai alat untuk meningkatkan motivasi kerja pegawai sehingga dapat dicapai kinerja yang baik dalam rangka pencapaian tujuan unit kerja dan organisasi.

d. Sebagai alat untuk mendorong atau membiasakan para atasan atau pejabat penilaian mengamati perilaku kerja pegawai sebagai totalitas hingga diketahui minat kemampuan serta kebutuhan pegawai.

Penilaian performasi kinerja terdiri dari 3 (tiga) langkah (Dessler, 1997):

1. Mendefinisikan jabatan, yaitu memastikan bahwa penilai dan yang dinilai sepakat terkait tugas dan standar jabatan.

2. Menilai kinerja, yaitu membandingkan antara kinerja aktual dengan standar yang telah ditetapkan.

3. Sesi umpan balik, yaitu saat membahas kinerja dan kemajuan pegawai serta membuat rencana pengembangan.

\subsection{Kompetensi}

Kompetensi merupakan bagian dalam dan selamanya ada pada kepribadian seseorang dan dapat mempredisikan tingkah laku dan performansi secara luas pada semua situasi dan job tasks (Spencer, 1993). Adapun ciri kompetensi adalah merupakan sekelompokan perilaku yang spesifik, dapat dilihat dan dapat diverifikasi yang secara reliable dan logis dapat dikelompokkan bersama serta sudah diidentifikasi sebagai hal-hal yang berpengaruh besar terhadap keberhasilan pekerjaan.

Jenis-jenis kompetensi ada 3 (tigas) diantaranya:

1. Kompetensi organisasi

2. Kompetensi pekerjaan atau teknis

3. Kompetensi Individual Karakteristik yang memiliki kompetensi dasar yaitu:
a. Motif
b. Traits
c. Konsep diri
d. Pengetahuan, dan
e. Keahlian 


\subsection{Metode 360 Degree Feedback}

Metode 360 degree feedback merupakan alat yang dapat membantu pegawai dalam mengoptimalkan performasi kinerja mereka, dengan memperoleh informasi kinerja dari berbagai sumber, termasuk rekan-rekan, atasan, bawahan dan dirinya sendiri. Informasi kinerja diperoleh dari dirinya sendiri dapat menjadi data pembanding dengan informasi yang diperoleh dari rekan kerja lainnya, agar mendapatkan pengaruh analisi perbedaan dan menunjukkan perbedaan seseorang menilai kinerjanya sendiri dan bagaimana orang lain melakukan penilaian pada kinerjanya. Metode 360 degree feedback digunakan beberapa perusahaan untuk mengidentifikasi dimensi kerja dan persetujuan adanya hal yang substansial untuk dilakukannya sebuat perbaikan (improvement) seperti yang digambarkan pada Gambar 1. (Ikatrinasari, 2018).

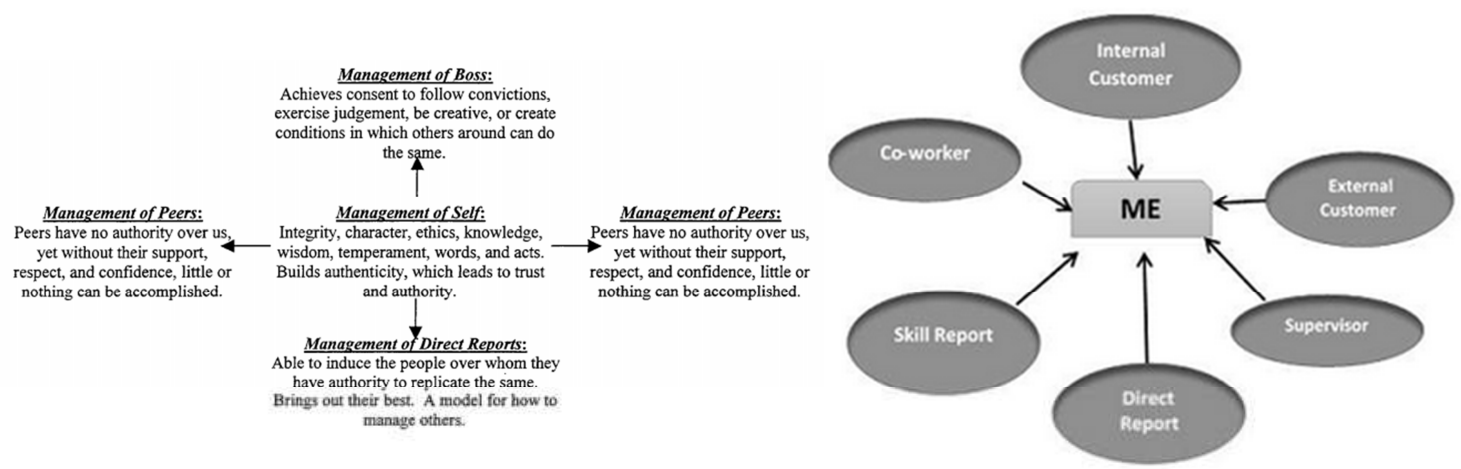

Gambar 1. 360 degree feedback

Penerapan penilaian performansi pegawai dengan menggunakan metode 360 degree feedback memberikan banyak kelebihan diantaranya:

1. Menurunkan kemungkinan bias

2. Meningkatkan kesadaran tentang kinerha yang diharapkan

3. Meningkatkan komitmen perbaikan

4. Memperbaiki persepsi diri tentang kinerjanya

5. Meningkatkan kinerja

6. Menurunkan hal-hal yang tidak bisa didiskusikan

7. Meningkatkan pengendalian karis

Proses kelebihan dari metode 360 degree feedback ini juga memiliki resiko dan kesalahan dalam sistem penilaian diantaranya:

a. Feedback negative dapat menyakiti hati pegawai

b. Individu tidak siap menerima feedback, sehingga tidak berpartisipasi secara baik

c. Anonim bisa diterima, namun informasinya dapat terdistorsi

d. Penilai memiliki beban berlebih dalam mengisi form penilaian

e. Tidak menilai partisipasi dalam keputusannya.

f. Ada sedikit perusahaan yang menjadi favorit bagi karyawannya.

g. Diantara karyawan tidak memiliki opini yang bernilai

h. Keputusan didasari oleh desas-desus

i. Karyawan tidak percaya/yakin dapat menyelesaikan pekerjaannya

Beberapa hal yang perlu dilakukan untuk meningkatkan keberhasilan sistem 360 degree feedback diantaranya:

1. Tidak dituliskan nama pada kuesioner

2. Penilai pertama memiliki pengetahuan tentang kinerja seseorang yang dievaluasi 
3. Feedback diartikan oleh orang tertarik dengan pengembangan diri

4. Ada follow up setelah mendapatkan feedback

5. Sistem digunakan untuk tujuan pengembangan

6. Penilai tidak kelelahan

7. Ada penekanan yang lebih pada behavior daripada result

8. Penilai hanya memberikan informasi tentang rating kinerja

9. Penilai dilatih terlebih dahulu

\subsection{Insentif atau Penghargaan}

Pemberian insentif atau penghargaan bisa secara singkat didefinisikan sebagai "extra pay for extra performance". Dengan demikian upah yang akan diberikan pada pegawai yang berprestasi akan diformulasikan sebagai:

$$
\text { Total upah }=\text { Upah dasar }+ \text { Insentif }
$$

Perencanaan pemberian insentif harus memperhatikan 7 (tujuh) langkah berikut ini:

1. Tetapkan sasaran rencana umum.

2. Tetapkan ukuran prestasi kinerja khusus.

3. Tetapkan sumber dana insentif.

4. Tetapkan satu metode untuk membagi dan mendistribusikan bagian perolehan pegawai.

Metode yang digunakan untuk menghitung insentif pegawai adalah sebagai berikut:

a. Persentase kenaikan nilai prestasi kerja dari standar yang ditetapkan \% kenaikan nilai prestasi kerja

$$
\text { prestasi kerja pegawai - prestasi kerja standar x 100\% }
$$

$$
\text { prestasi kerja standar }
$$

b. Pemberian insentif berdasarkan presentasi kenaikan tersebut. Insentif akan diberikan berdasarkan persentase kenaikan nilai prestasi kerja yang dicapai oleh pegawai. Persentase kenaikan nilai prestasi kerja dari standar yang ditetapkan yang ditunjukkan oleh seorang pegawai akan dibandingkan dengan total persentase kenaikan nilai prestasi kerja seluruh pegawai. Sehingga akan didapatkan sebuah nilai akhir, yang mana nilai akhir ini akan dikalikan dengan dana yang dialokasikan untuk insentif untuk mengetahui insentif yang diperoleh.

5. Tetapkan bentuk pembayaran yang digunakan

6. Tetapkan seberapa sering bonus dibayarkan

7. Kembangkan sistem keterlibatan karayawan

\section{METODOLOGI}

Penelitian ini merupakan penelitian terapan yang bertujuan untuk memecahkan masalah yang dihadapi perusahaan dalam melakukan penilaian kinerja yang dianggap memiliki subjektivitas yang tinggi sehingga dibutuhkan rekomendasi perbaikan dalam penilaian kinerja. Hasil dari penelitian ini diarahkan sebagai tindakan perbaikan (corrective action) terhadap penilaian kinerja. Objek penelitian diantarannya tenaga kependidikan di PTS X. 
Sumber data yang diperoleh pada penelitian ini merupakan sumber data primer yang dikumpulkan melalui review literature penelitian dan usulan kuisioner 360 degree feedback meliputi penilaian kompetensi yang diperoleh dari atasan, rekan kerja, bawahan dan diri sendiri. Data sekunder berupa visi dan misi perusahaan, tujuan organisasi dan struktur organisasi perusahaan.

Prosedur pelaksanaan penelitian dilakukan dengan mengikuti beberapa tahapan, yaitu:

1. Menentukan tujuan penilaian kinerja

2. Memberikan batasan terhadap variabel penilaian yang menjadi dasar penilaian kinerja.

3. Menyusun pertanyaan-pertanyaan pada kuisioner melalui literature penelitian

\section{HASIL DAN PEMBAHASAN}

Proses penilaian kinerja 360 degree feedback dilakukan dengan menilai atasan, bawahan serta peer atau rekan kerja. Penilaian 360 degree feedback dilakukan dengan perumusan :

$$
\text { Total Penilaian }=\frac{\text { Hasil Penjumlahan Kuisioner }}{\text { Jumlah Item Penilaian }} \times 100 \%
$$

Hasil persentasi penilaian kuisioner dikategorikan pada grade :

Tabel 1.1 Grade Hasil Persentasi Penilaian Kuisioner

\begin{tabular}{cccc}
\hline $80 \%-100 \%$ & $=\mathrm{A}$ \\
\hline $70 \%-79 \%$ & $=$ & $\mathrm{A}-$ \\
\hline $60 \%-69 \%$ & $=$ & $\mathrm{B}+$ \\
\hline $50 \%-59 \%$ & $=\mathrm{B}$ \\
\hline $0 \%-49 \%$ & $=\mathrm{C}$ \\
\hline
\end{tabular}

Usulan penerapan kuisioner ini diharapkan mampu untuk menjadi pertimbangan pihak kepegawaian pada Perguruan Tinggi Swasta untuk dapat mempertimbangkan target performansi kinerja pegawai dengan metode 360 degree feedback. Metode ini juga dapat mempengaruhi pegawai untuk dapat mengevaluasi performansi diri sendiri, dan penilaian dari pegawai lain dengan kesesuaian keterkaitan kinerja dengan hasil grade yang didapatkan sebagai pertimbangan penghargawaan (reward).

\section{DAFTAR PUSTAKA}

Aguinis, H. (2008). Performance Managament. 2nd., New York, NY : Prentice Hall

Dessler, Gary. (1997). Manajemen Sumber Daya Manusia. Edisi ke-7, Alih Bahasa, Jilid 1 \& Jilid 2, Prenhallindo, Jakarta

Ginting, Abadi dan Eka Fachrizal. (2013). Penilaian Kinerja Karyawan dengan Menggunakan Metode 360 Degree Feedback pada Hotel XYZ Medan. Universitas Sumatera Utara : Medan

Ikafitrinasari, Zulfa Fitri,. (2018). Performance Management and Employee Development Performance Managemen Skill (Modul Perkuliahan), Universitas Mercu Buana : Meruya, Jakarta Barat

Ramdhaniah, Chici, dan Irsutami. (2011). Pengembangan Pengukuran Kinerja dengan Pendekatan Balance Score Card (Studi Kasus pada Politeknik Negeri Batam). Batam

Spencer, M. Lely \& Signe. (1993). Competence At Work. Models for Superior Performance John Wiley \& Sons Inc.

Stoner, James, A.F., Freeman Edward and Daniel Gilbert. 1996. Manajemen. Alih Bahasa. Jilid 1 \& Jilid 2. Simon \& Schuster (Asia Pte. Ltd). Jakarta 


\section{LAMPIRAN}

Lampiran Usulan Kuisioner Pegawai Perguruan Tinggi.

\section{Form Penilaian Pegawai Perguruan Tinggi}

\section{Nama Pegawai \\ Departemen \\ Tanggal \\ Nama Penilai}

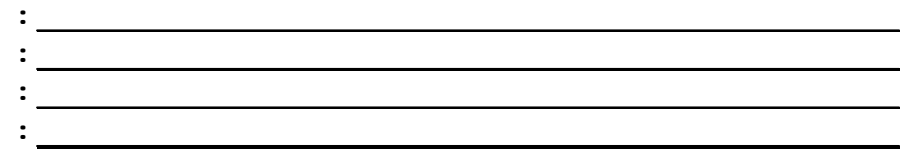

\begin{tabular}{|c|c|c|c|c|c|c|}
\hline Unsur Penilaian & : & Amat Baik & Baik & Sedang & Cukup & Kurang \\
\hline (bobot) & $:$ & 5 & 4 & 3 & 2 & 1 \\
\hline $\begin{array}{l}\text { Quantity work, jumlah kerja yang } \\
\text { dilakukan dalam suatu periode waktu } \\
\text { dan kesiapannya }\end{array}$ & : & & & & & \\
\hline $\begin{array}{l}\text { Quality of work, kualitas kerja } \\
\text { berdasarkan syarat-syarat kesesuaian } \\
\text { dan kesiapannnya. }\end{array}$ & : & & & & & \\
\hline $\begin{array}{l}\text { Job knowledge, luasnya pengetahuan } \\
\text { mengenai pekerjaan dan } \\
\text { keterampilannya. }\end{array}$ & : & & & & & \\
\hline $\begin{array}{l}\text { Creativeness, keaslian gagasan- } \\
\text { gagasan yang dimunculkan dan } \\
\text { tindakan-tindakan untuk } \\
\text { menyelesaikan persoalan-persoalan } \\
\text { yang timbul. }\end{array}$ & & & & & & \\
\hline $\begin{array}{l}\text { Cooperation, kesetiaan untuk } \\
\text { bekerjasama dengan orang lain. }\end{array}$ & & & & & & \\
\hline $\begin{array}{l}\text { Dependability, kesadaran dan } \\
\text { kepercayaan dalam hal kehadiran dan } \\
\text { penyelesaian kerja. }\end{array}$ & & & & & & \\
\hline $\begin{array}{l}\text { Initiative, semangat untuk } \\
\text { melaksanakan tugas-tugas baru dan } \\
\text { dalam memperbesar tanggung } \\
\text { jawabnya. }\end{array}$ & & & & & & \\
\hline $\begin{array}{l}\text { Personal qualities, menyangkut } \\
\text { kepribadian, kepemimpinan, } \\
\text { keramah-ramahan, dan integritas } \\
\text { pribadi. }\end{array}$ & & & & & & \\
\hline
\end{tabular}

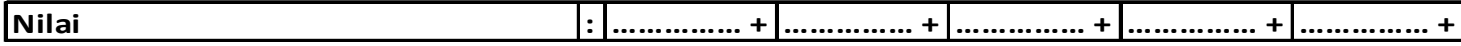

Total Nilai

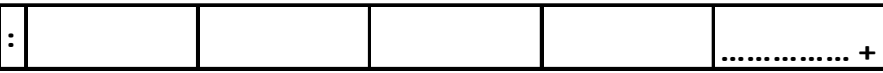

